
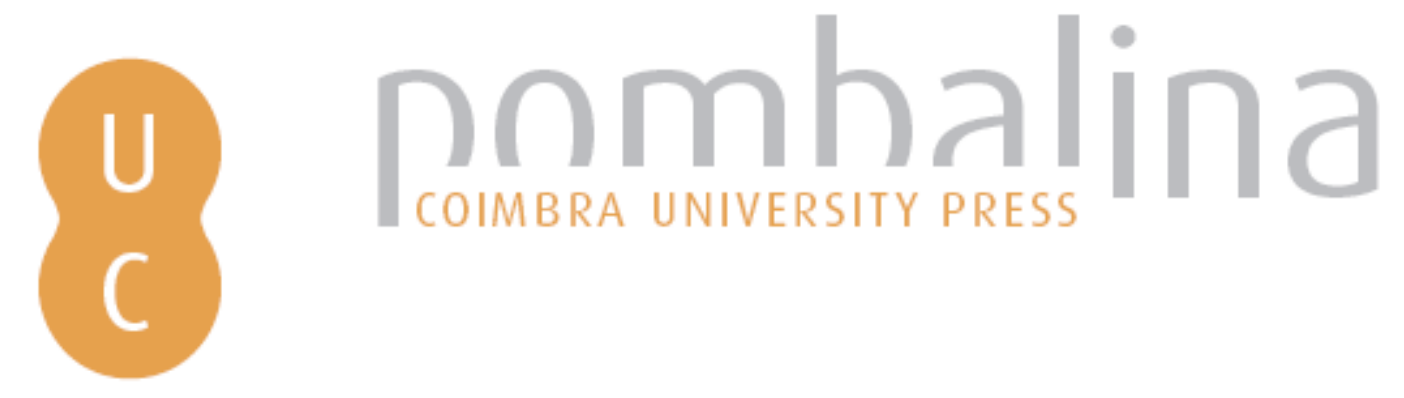

\title{
Fire intensity, individual protective clothing and firefighting safety
}

\author{
Autor(es): \\ Raimundo, António M.; Oliveira, A. Virgílio M.; Quintela, Divo A.; \\ Figueiredo, A. Rui
}

Publicado por: Imprensa da Universidade de Coimbra

URL

persistente: URI:http://hdl.handle.net/10316.2/44566

DOI: $\quad$ DOI:https://doi.org/10.14195/978-989-26-16-506_49

Accessed : $\quad$ 26-Apr-2023 16:01:39

A navegação consulta e descarregamento dos títulos inseridos nas Bibliotecas Digitais UC Digitalis, UC Pombalina e UC Impactum, pressupõem a aceitação plena e sem reservas dos Termos e Condições de Uso destas Bibliotecas Digitais, disponíveis em https://digitalis.uc.pt/pt-pt/termos.

Conforme exposto nos referidos Termos e Condições de Uso, o descarregamento de títulos de acesso restrito requer uma licença válida de autorização devendo o utilizador aceder ao(s) documento(s) a partir de um endereço de IP da instituição detentora da supramencionada licença.

Ao utilizador é apenas permitido o descarregamento para uso pessoal, pelo que o emprego do(s) título(s) descarregado(s) para outro fim, designadamente comercial, carece de autorização do respetivo autor ou editor da obra.

Na medida em que todas as obras da UC Digitalis se encontram protegidas pelo Código do Direito de Autor e Direitos Conexos e demais legislação aplicável, toda a cópia, parcial ou total, deste documento, nos casos em que é legalmente admitida, deverá conter ou fazer-se acompanhar por este aviso.

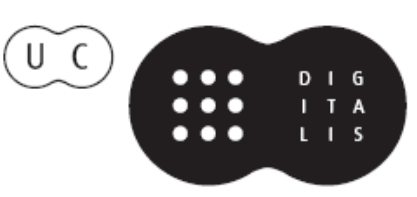




\section{ADVANCES IN}

\section{FOREST FIRE RESEARCH}

\section{8}

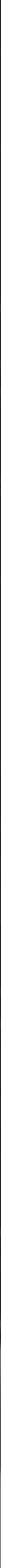




\title{
Fire intensity, individual protective clothing and firefighting safety
}

\author{
António M. Raimundo ${ }^{1 *}$; A. Virgílio M. Oliveira ${ }^{2}$; Divo A. Quintela ${ }^{1}$; A. Rui Figueiredo ${ }^{1}$ \\ ${ }^{1}$ ADAI-LAETA, Department of Mechanical Engineering, Faculty of Sciences and Technology of \\ the University of Coimbra, Portugal. \{antonio.raimundo@dem.uc.pt*\} \\ ${ }^{2}$ Department of Mechanical Engineering, Coimbra Institute of Engineering of Polytechnic Institute \\ of Coimbra, Portugal. \{avfmo@mail.isec.pt\}
}

\begin{abstract}
The main objective of this work is to establish useful guide-lines for secure firefighting, namely the evaluation of the influence of fire intensity, personal protective clothing properties and application of body cooling techniques on safety during firefighting operations. The physiological reaction of men exposed to these conditions is obtained by numerical simulation using a software implemented by the authors.

The protocol adopted submits the firefighter to four phases: neutral, pre-firefighting, firefighting and recovering. On the fire-fighting phase, the properties of the firefighter protective clothing depend on the test settings (values of intrinsic insulation between 0 and 9 clo were considered). In this phase, the firefighter, doing hard work $(M=3.0 \mathrm{met})$, is exposed to an impinging radiation in an environment with $T_{a i r}=T_{m r}=50^{\circ} \mathrm{C}$. Incident radiation fluxes $\left(I_{r a d}\right)$ between 0 and $40 \mathrm{~kW} \mathrm{~m}^{-2}$ were considered. On the recovering period, the firefighter is far from the fire and has a low level of activity $(M=1.2 \mathrm{met})$. Six alternative body cooling techniques were analyzed, which are applied only during the recovering period: passive cooling; use of an ice jacket; immersion of hands and forearms in water at $20^{\circ} \mathrm{C}$ and at $10^{\circ} \mathrm{C}$; use of an ice jacket reinforced by immersion of hands and forearms in water at $10^{\circ} \mathrm{C}$; and all body (except head and neck) immersion in water at $25^{\circ} \mathrm{C}$.

From a safety point of view, the most important indicator seems to be the time delay for the onset of heat stroke (fainting). The threshold for introversion is a good indicator to assess the exposure periods that must not be exceeded.

As expected, the predicted results indicate that the firefighter thermal stress level depends primarily on the intensity of the incoming radiation, on the time of exposure to it and on the clothing thermal insulation. Time safety intervals decrease with the increase of the impinging thermal radiation and increase with the insulation of the ensemble. However, clothing high thermal insulation can hide dangerous situations. Thus, a convenient control of the duration of firefighting periods it is crucial.

For the situation of $I_{\text {rad }}=5 \mathrm{~kW} \mathrm{~m}^{-2}$ and an active fighting period of 20-minutes, the cooling techniques tested can be ordered from the less effective to the highest one as: $\left.6^{\text {th }}\right)$ passive cooling; $5^{\text {th }}$ ) use of an ice jacket; $4^{\text {rd }}$ ) immersion of hands and forearms in water at $20^{\circ} \mathrm{C} ; 3^{\text {rd }}$ ) the same but with water at $10^{\circ} \mathrm{C} ; 2^{\text {nd }}$ ) use of an ice jacket reinforced by immersion of hands and forearms in water at $10^{\circ} \mathrm{C}$; and $1^{\text {st }}$ ) all body (except head and neck) immersion in water at $25^{\circ} \mathrm{C}$. Among the tested, the strategy of immersion the entire body in water at $25^{\circ} \mathrm{C}$ is undoubtedly substantially much more effective than the others.
\end{abstract}

Keywords: Safety firefighting; Human thermoregulation modelling; Times for the onset of heat-related illness

\section{Introduction}

The high level of physical work required during firefighting leads to high rates of metabolic heat production. Additionally, the heat fluxes gained by the body due to the impinging of thermal radiation from flames, the exchange of infrared radiation with the surroundings, the convection with surrounding hot gas (air and smoke), the conduction from heated grounds and the solar radiation should also be considered. If, as a result of this combination of heat gains, the hypothalamus temperature exceeds certain values, important and undesirable incidents can affect firefighters (Carter et al. 1999; Mündel 
et al. 2006; Lopez et al. 2008; Barr et al. 2009; Raimundo and Figueiredo 2009), namely introversion (violent sweating, misleading, amnesia, etc.), superficial skin damages (pain and burn degree 1), heat stroke (fainting, stop of sweating, central nervous system alteration, etc.) and permanent injuries (burn degree greater than 1 , brain damage or, in the more serious cases, death).

Wearing high thermal insulating protective clothing reduces the gain of external heat, but also blocks the release of the heat produced and restricts movements. Therefore, firefighting safety demands the wearing of clothing with thermophysical properties appropriated to each firefighting feature, which include the assessment of the required activity level and of the thermal environment. These matters are described in the literature and are known by the firefighters which are aware of the individual protective clothing that should be used in each kind of fire (Sharkey 1999; McLellan \& Selkirk 2005; Bröde et al. 2010; Carballo-Leyenda et al. 2017; McQuerry et al. 2018).

To satisfy all the demands of the firefighting activity, it might be necessary to use recovery strategies for physical recuperation and for body cooling as a way to attenuate the thermal stress (Carter et al. 1999; Selkirk et al. 2004; Giesbrecht et al. 2007; Chou et al. 2008; Lopez et al. 2008; Barr et al. 2009; Hostler et al. 2010; Colburn et al. 2011; Abreu et al. 2014). The purpose of the body cooling process after the firefighting activity is to restore the thermophysiological balance of the body in the shortest time possible and thus avoid harmful health effects and, at the same time, try to help the recovery of the individual for any subsequent activity.

Nevertheless, despite the significant knowledge regarding the fire intensity, the level of activity required during firefighting, the individual protective clothing to be used by the firefighter and the application of recovering techniques, some topics still remain unanswered, namely what is the maximum time of exposure for safe firefighting? The objective of this work is to contribute to this issue.

Experimental studies concerning the thermophysiological response of firefighters carrying out typical firefighting activities (both structural and wildland), wearing the recommended protective clothing and exposed to environments that are representative of these fires have already been published (Carballo-Leyenda et al. 2017; Fontana et al. 2017; McQuerry et al. 2018; among others). However, due to safety reasons of the individuals involved, these trials always terminate before firefighters reach levels of hyperthermic stress with the potential to cause heat-related illnesses. This drawback is overcome by using validated models to simulate the human body thermophysiological response when exposed to very hot environments, with high levels of impinging thermal radiation.

\section{The Calculation Tool}

To obtain the results presented in this study, a computer program implemented by the authors (Raimundo and Figueiredo, 2009; Raimundo et al. 2012 \& 2015) is used for the simulation of heat and mass transfer and thermophysiological response of a male firefighter exposed to extreme environmental conditions, such as those occurring in the proximity of a high intensity fire front. This program is composed by several modules. However, for present purposes only the following ones are used $(i)$ person thermophysiological response, (ii) heat and water transport through the clothing, (iii) heat (by conduction, convection and radiation) and mass exchange between the external surface of clothing (or skin) and the environment and surroundings, (iv) start and evolution of skin injuries (pain and burn) and ( $v$ ) detection of specific incidents within the human being. Due to its interdependency, all modules run iteratively in each time step until a specific convergence criterion is reached.

The module for simulation of human's thermophysiological response is based on the Stolwijk (1971) thermoregulation model of 25 nodes, improved with knowledge found in the literature (e.g., Konz et al. 1977; Fiala et al. 1999; Tanabe et al. 2002). The thermoregulation model represents the human body by 111 nodes, corresponding to 22 segments, each one formed by 5 layers (core, muscle, fat, skin and clothing) and the central blood compartment (the $111^{\text {th }}$ node). The model was 
implemented for an average man with $74.43 \mathrm{~kg}$ and $1.72 \mathrm{~m}\left(1.869 \mathrm{~m}^{2}\right.$ of skin). For an individual with other anthropometric data, the appropriated coefficients are proportionally changed as a function of its body weight and skin area. The loss of heat by respiration is supposed to occur across the elements of the pulmonary tract. The repartition coefficients proposed by Fiala et al. (1999) were considered.

The simulation of heat and water transport through the clothing is based on the formulation proposed by Havenith et al. (2002). The calculations are made for each specific human body segment. Then, individual values of the local clothing parameters (intrinsic insolation, mass, specific heat, vapour permeability and radiation emissivity) must be specified for each of the 22 human body segments considered. Each section is either entirely clothed or completely nude.

The convective heat and mass transfer phenomena are predicted using the empirical relations proposed by Quintela et al. (2004) for natural convection and by Havenith et al. (2002) for forced convection. The exchange of heat by radiation between the external surfaces of the segments of the human body and between them and the surroundings, is determined by a set of expressions established by Raimundo et al. (2004).

The modeling of skin burn process implemented in the software is based on Henriques' theory [Henriques, 1947], which represents the skin thermal damage as chemical rate phenomena. As they do not start at the same instant, the prediction of the skin pain threshold is also useful. This is important because, as reported by Stoll and Greene (1959), when the pain is felt, it is often too late to avoid a $2^{\text {nd }}$ degree skin burn or, in some extreme situations, a heat-stroke or even death. Empirical correlations have been developed that allow the prediction of the time until pain is felt, some of them reported in Wenger (1988) and SFPE guide (2000). In the present program, the onset of skin pain is marked when epidermis-dermis interface temperature $\left(T_{\text {edi }}\right)$ reaches $45^{\circ} \mathrm{C}$ (Havenith and Heus 2000) or when Henriques (1947) integral injury parameter $(\Omega$ ) equals 0.53 , depending on what occurs first (generally, $\left.T_{\text {edi }}=45^{\circ} \mathrm{C}\right)$.

Each run can simulate up to 20 consecutive scenarios (phases), each one representing different conditions in terms of: posture, orientation, activity, intake of food/drinks, clothing, thermal environment characteristics and impinging of thermal radiation from 6 directions (cardinal, top and bottom). The global algorithm is applied to each specific human body segment, but always considering its influence and interdependence with the global thermal state of the body.

To understand the significance of the calculated body temperatures, it is necessary to identify the values for which there is a probability of occurrence of specific incidents in the human body. Normally, the rectal temperature is used to identify the risk of thermal injuries. Nevertheless, the temperature of blood reaching the hypothalamus is regarded as a major afferent stimulus for the intensity of the effective response of sweating, vasomotor activity and shivering. Then, a better relationship may be expected between hypothalamus temperature $\left(T_{\text {hyp }}\right)$ and the various physiological and sensory states (Pascoe et al. 1994; Kenney et al. 2004; Raimundo and Figueiredo 2009; Raimundo et al. 2012). In the program's module for detection of specific incidents, the temperature limits are set as function of the hypothalamus temperature ( $T_{\text {hyp }}$ ) following the Pascoe et al. (1994) scale: $\leq 25^{\circ} \mathrm{C} \rightarrow$ death, $\leq 28^{\circ} \mathrm{C} \rightarrow$ ventricular fibrillation, $\leq 30^{\circ} \mathrm{C} \rightarrow$ stop shivering and fainting, $\leq 34^{\circ} \mathrm{C} \rightarrow$ introversion and violent shivering, $34<T_{\text {hyp }}<39^{\circ} \mathrm{C} \rightarrow$ normal thermoregulation, $\geq 39^{\circ} \mathrm{C} \rightarrow$ introversion and violent sweating, $\geq 41^{\circ} \mathrm{C} \rightarrow$ heat-stroke (stop sweating and fainting), $\geq 42^{\circ} \mathrm{C} \rightarrow$ brain damage (permanent injuries) and $\geq 44^{\circ} \mathrm{C} \rightarrow$ death.

The evaluation, test and validation of the ability of HuTheReg software to predict the human body thermophysiological behavior was performed by comparing the program's predictions with experimental results. The validation process spanned a wide-range of conditions, which included different kinds of thermal environments, of exposures, of exercise intensities and of clothing. As stated in previous papers (Raimundo and Figueiredo 2009; Raimundo et al. 2015), a good agreement was

Advances in Forest Fire Research 2018 - Page 456 
achieved, which indicates an interesting capacity of the program to predict the thermophysiological response of the human body to a wide variety of conditions.

\section{Problem Description}

The protocol adopted in the present work submits the firefighter to 3 or 4 phases: neutral (stabilization), pre-firefighting, firefighting and recovering. The last one is considered only in the simulations to evaluate human body cooling techniques.

The neutral phase aims to ensure that all firefighters subjected to the protocol depart equally and in a state of thermal neutrality.

In the pre-firefighting phase, that starts 1 hour before the beginning of the thermal impact, the individual is exposed to an external environment with $T_{\text {air }}=T_{m r}=35^{\circ} \mathrm{C}, v_{\text {air }}=5 \mathrm{~m} / \mathrm{s}, R H_{\text {air }}=50 \%$, performs moderate work $(M=1.5$ met: this task involves making preparations, moving towards the fire scene, making supporting activities, etc.) and wears a suit (composed by shirt, briefs, pants, socks and boots) with a global intrinsic insulation $I_{c l}=1.0 \mathrm{clo}$, a vapor permeability $i_{v p}=0.47$, a radiative reflectivity $\rho=0.1$ and a total mass $m_{c l}=3.08 \mathrm{~kg}$ (boots included).

On the fire-fighting phase, the firefighter, doing hard work for which $M=3.0$ met, is exposed to an impinging radiation, in an environment with $T_{\text {air }}=T_{m r}=50^{\circ} \mathrm{C}, v_{\text {air }}=5 \mathrm{~m} / \mathrm{s}$ and $R H_{\text {air }}=50 \%$. In this phase, incident radiation fluxes $\left(I_{\mathrm{rad}}\right)$ between 0 and $40 \mathrm{~kW} \mathrm{~m}^{-2}$ were tested and the properties of the firefighter protective clothing depend on the test settings. Namely, they were considered clothing's with global values between 0 and 9 clo for $I_{c l}$, between 0 and 1 for $i_{v p}$ and between 0.1 and 1.0 for $\rho$.

The recovering phase (time break and cooling) aims to lower the heat stored in firefighter, then also his body temperatures. On this phase, the firefighter: is far from the fire front $\left(I_{r a d}=0\right)$; has a low level of activity $(M=1.2 \mathrm{met})$; is wearing his protective clothing, but without the helmet, the balaclava, the coat, and the gloves (in one case only in shorts); and is in a shaded location with $T_{a i r}=T_{m r}=30^{\circ} \mathrm{C}$, $v_{\text {air }}=3 \mathrm{~m} / \mathrm{s}$ and $R H_{\text {air }}=50 \%$.

\section{Results and Discussion}

As reported elsewhere [Rossi et al. 2011; Fontana et al. 2017; among others], during firefighting activities the firefighters can be exposed to radiant heat fluxes of up to $40 \mathrm{~kW} \mathrm{~m}^{-2}$ in environments with temperatures greater than $250^{\circ} \mathrm{C}$ and high relative humidities. Furthermore, levels of metabolic rates up to 8 met can be required during large periods of time. These conditions cause considerable thermoregulatory strain and represent a substantial risk for the onset of health-related incidents within the firefighter [Fontana et al. 2017]. As far as safety is concerned, the most important indicators seem to be the times delays for the onset of heat-stroke (fainting) and of skin pain, mainly the first one. The threshold for introversion is a good indicator for exposure limits that must not be exceeded.

Almost all existing regulations and standards on fire safety stipulate, as main risk assessment parameter for fire exposure, the thermal incident radiation on the human body coming directly from the fire $\left(I_{r a d}\right)$ [Raj 2008, EN 1473/2016]. That does not includ solar radiation and other thermal radiation exchanges. It is from $I_{\text {rad }}$ that all the other parameters are defined, such as the safety distance, the maximum exposure times, the level of protection required, etc.

Normally, regulations and standards postulate that an incident radiation flux up to $I_{\text {rad }}=1.5 \mathrm{~kW} \mathrm{~m}^{-}$ 2 is tolerable for persons not wearing fire protective clothing. For people dressed in fire protective ensembles, exposures to incident radiation fluxes up to $I_{\text {rad }}=5 \mathrm{~kW} \mathrm{~m}^{-2}$ are considered of acceptable risk. An exposure to an incident radiation flux higher than $I_{r a d}=8 \mathrm{~kW} \mathrm{~m}^{-2}$ is only considered minimally safe if a suitable fire protective ensemble is used. 
The aforesaid stipulations are too simplistic because, in order to establish the risk of potential heatrelated illness, the knowledge of $I_{\text {rad }}$ it is not enough; moreover it is necessary to take into account many other factors such as: the initial thermal state of the person; its anthropological characteristics; the area of the body exposed to the incident radiation; the intensity of the physical activity exerted; the thermo-hygrometric characteristics of clothing $\left(I_{c l}, m_{c l}, i_{v p}\right.$ and $\left.\rho\right)$; and the remaining environmental conditions ( $I_{\text {solar }}, T_{m r}, T_{\text {air }}, v_{\text {air }}, \mathrm{RH}_{\text {air }}$ and smoke level). In addition, it should be taken into consideration the fact that the regulations and the norms establish the human risk level based on the ratio between the expected exposure time threshold of fainting due to heat-stroke and / or of appearance of permanent injuries (skin burn degree 2, permanent brain damage) and the time required to take evasive actions and/or to initiate mitigation measures. Then, since they were not specifically postulated for firefighting activities, the aforesaid stipulations can hide situations of potential risk to firefighters, particularly the cases $I_{r a d}=1.5$ and $I_{r a d}=5 \mathrm{~kW} \mathrm{~m}^{-2}$. Therefore, in this work particularly attention is given to situations involving these two impinging thermal radiations.

The onset of heat-related diseases within the firefighter are show in Figures 1 and 2 for impinging thermal radiations of $I_{r a d}=1.5 \mathrm{~kW} \mathrm{~m}^{-2}$ and $I_{r a d}=5 \mathrm{~kW} \mathrm{~m}^{-2}$, respectively. In Figures 1 and $2(a, b$ and $c$ ) the evolutions of hypothalamus, rectal and maximum skin temperatures with time are represented for 3 different levels of clothing insulation, namely: $I_{c l}=1.21$ clo (complete ensemble with weak insulation), $I_{c l}=1.59$ clo (current for wildland firefighting) and $I_{c l}=2.63$ clo (current for structural firefighting). The four horizontal lines identify the threshold values for the beginning of introversion, of heat stroke, of lethal and of skin pain temperatures, as specified before. The start of the fire thermal impact occurs at instant zero on the time axis. Structural firefighting includes the fight of building and factories fires. Figures $1 d$ and $2 d$ shown the time (after fire impact) for the beginning of skin pain and burn degree 1, of introversion, of heat stroke, of brain damage and of death as function of the firefighter clothing insulation. For $I_{\text {rad }}=1.5 \mathrm{~kW} \mathrm{~m}^{-2}$ skin pain and skin burn degree 2 only "occur" after death, then they are not shown in Figure $1 d$. As presented in Figure 2, for $I_{\text {rad }}=5 \mathrm{~kW} \mathrm{~m}^{-2}$ skin pain starts before heat-stroke until $I_{c l}<1.21$ clo (incomplete covering of firefighter skin) and "after" death for $I_{c l} \geq 1.21$ clo (complete clothing); skin burn degree 2 only "occur" after death, then it is not shown in Figure $1 d$.
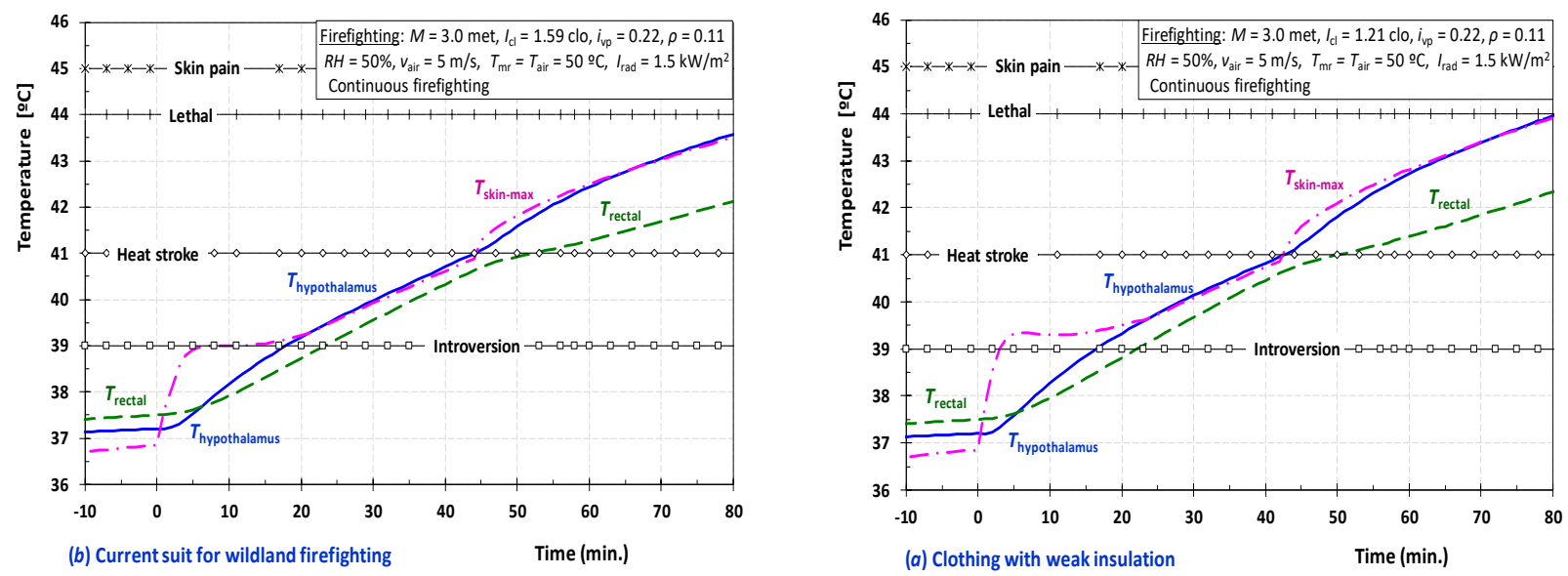

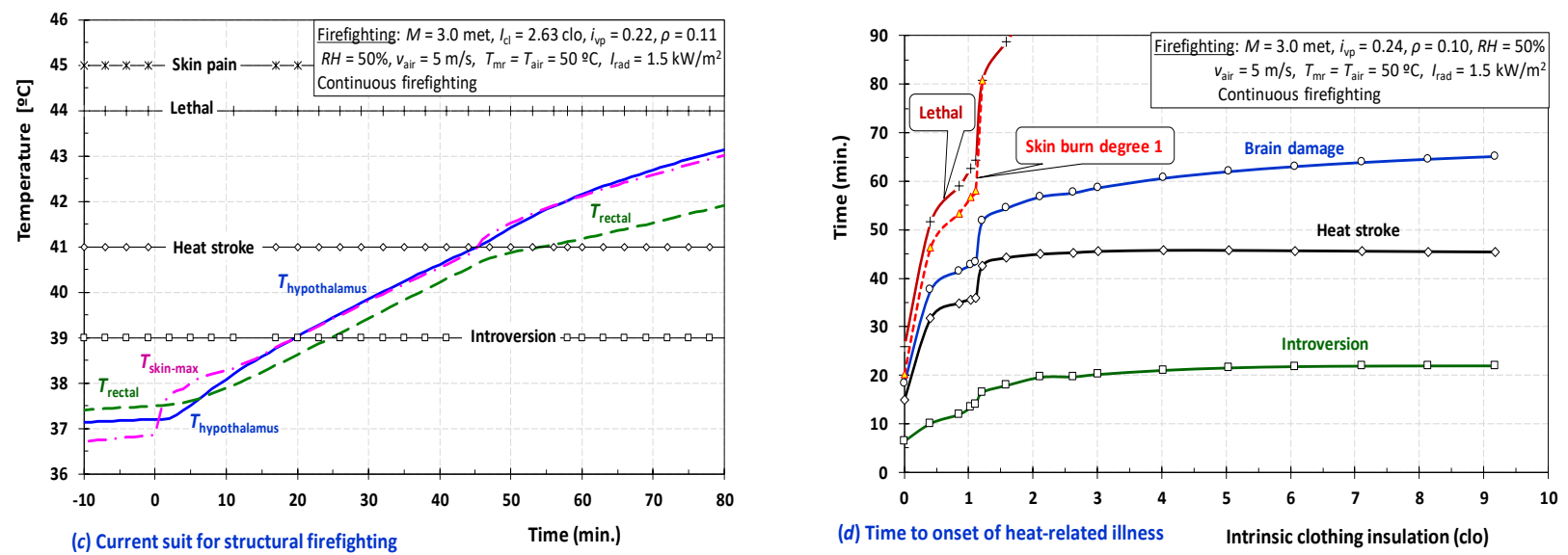

Figure 1 - Incident thermal radiation $I_{r a d}=1.5 \mathrm{~kW} \mathrm{~m}^{-2}:(a, b$ and $c)$ Time evolution of temperatures on hypothalamus ( - ), rectal ( - - -) and maximum value of skin (-:- -) and limiting temperatures for the beginning of introversion, heat stroke, lethal and skin pain, for a complete ensemble with: a) $I_{c l}=1.21 \mathrm{clo}$ ), b) $I_{c l}=1.59$ clo and c) $I_{c l}=2.63 \mathrm{clo}$; and (d) Time (after fire impact) for the beginning of skin pain, of introversion, of heat stroke, of brain damage and of death as function of clothing insulation.

It is possible to observe from Figures 1 and $2(a, b$ and $c)$ that the increasing of clothing thermal insulation implies more temperature uniformity between human body parts. For normal thermal environments, the rectal temperature is one of the highest in the human body and is often taken as representative of the body core temperature. This is no longer valid for situations where human body is exposed to extreme thermal conditions, where rectal temperature is a bad indicator for the maximum body core temperature. This is the reason why it was not used in this work as a criterion for the detection of specific undesired reactions within the man; instead the hypothalamus temperature is considered a more appropriated threshold.
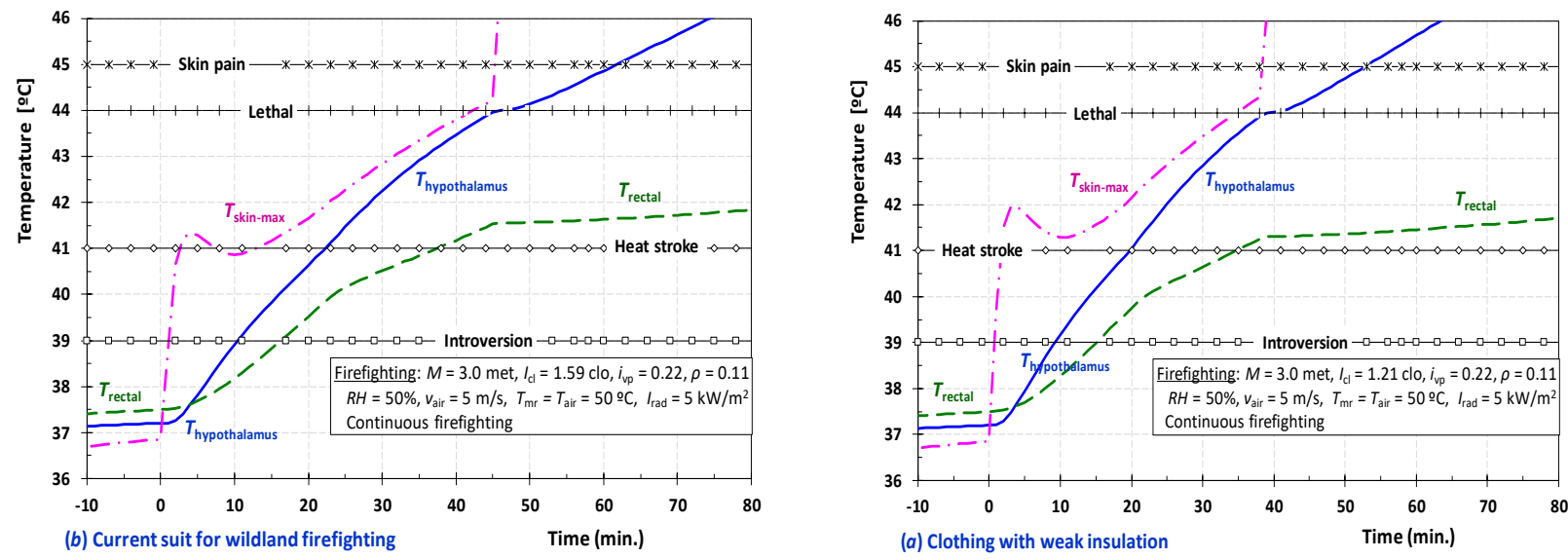

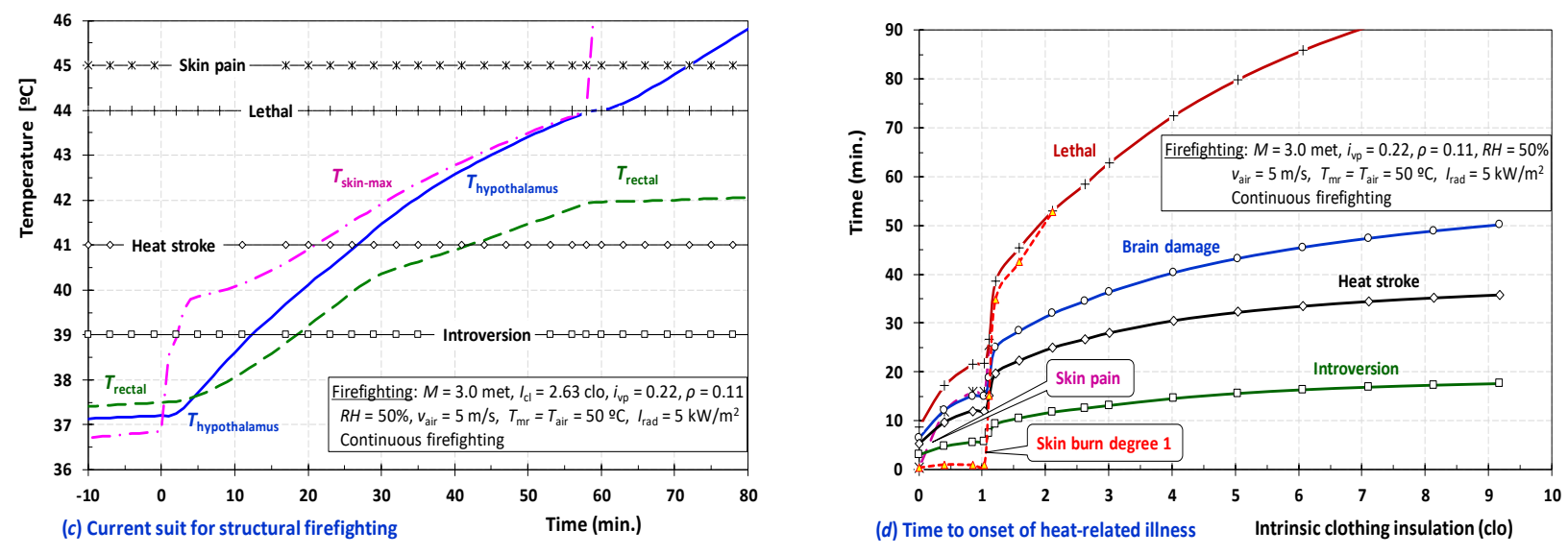

Figure 2 - Incident thermal radiation $I_{r a d}=5 \mathrm{~kW} \mathrm{~m}^{-2}:(a, b$ and $c)$ Time evolution of temperatures on hypothalamus ( - ), rectal ( - - -) and maximum value of skin (- - - -) and limiting temperatures for the beginning of introversion, heat stroke, lethal and skin pain, for complete ensemble with: a) $\left.\left.I_{c l}=1.21 \mathrm{clo}\right), \mathrm{b}\right) I_{c l}=1.59 \mathrm{clo}$ and c) $I_{c l}=2.63 \mathrm{clo}$; and (d) Time (after fire impact) for the beginning of skin pain, of introversion, of heat stroke, of brain damage and of death as function of clothing insulation.

Figures $1 d$ and $2 d$ present the instants of probable onset of heat-related illness as functions of the global value of clothing insulation. In both situations these periods increase with global value of clothing thermal insulation, namely for the heat-stroke and death threshold. This effect is evident in the range between 1 to 3 clo, becoming less pronounced for higher values. Moreover, protective clothing ensembles with insulating values above 3 clo will restrict firefighter movements and then they are not practical to use.

In both situations shown in Figures $1 d$ and $2 d$, whatever clothing insulation, skin burn degree 1 starts before skin pain. For $I_{r a d}=1.5 \mathrm{~kW} \mathrm{~m}^{-2}$ and independently of clothing insulation, skin pain and skin burn degree 2 only "occur" after death, then, for fires of this intensity, skin pain is not a useful alert in terms of human safety. For $I_{\mathrm{rad}}=5 \mathrm{~kW} \mathrm{~m}^{-2}$ and if the skin is not complete covered $\left(I_{c l}<1.21 \mathrm{clo}\right)$, skin pain starts in very short exposure times after fire impact and before heat-stroke. The time interval between the onset of skin pain and of heat-stroke is also very short. In these conditions skin pain works as an alert signal, inducing the firefighter to escape quickly from the fire front line to avoid fainting and to be trapped by the fire. Then, without a complete covering of skin, is not possible to fight fires from which the impinging radiation is $I_{r a d} \geq 5 \mathrm{~kW} \mathrm{~m}^{-2}$. Nevertheless, this cannot be taken as a safety rule, as for complete firefighter ensembles the heat-stroke can be reached before skin pain, which obviously poses a crucial problem for personal safety.

From the values presented in Figures 1 and 2, it can be stated that firefighting activities requires the wearing of complete protective ensembles with $I_{c l} \geq 1.21$ clo. For fires with $I_{r a d} \leq 1.5 \mathrm{~kW} \mathrm{~m}^{-2}$ it is enough to wear clothing with insulation equal or lower $I_{c l}=1.59 \mathrm{clo}$ (current for wildland firefighting) and for fires with $I_{\mathrm{rad}} \leq 5 \mathrm{~kW} \mathrm{~m}^{-2}$ an insulation equal or lower than $I_{c l}=2.63$ clo (current suit for structural firefighting) it is enough.

The onset of heat-related diseases within the firefighter as function of the impinging thermal radiation $\left(I_{r a d}\right)$ is show in Figure $3 a$ for an ensemble with $I_{c l}=1.59$ clo (current for wildland firefighting) and in Figure $3 b$ for a suit with $I_{c l}=2.63$ clo (current for structural firefighting). If $I_{c l}=2.63$ clo skin burn degree 2 only "occur" after death, then it is not shown in Figure $3 b$. 

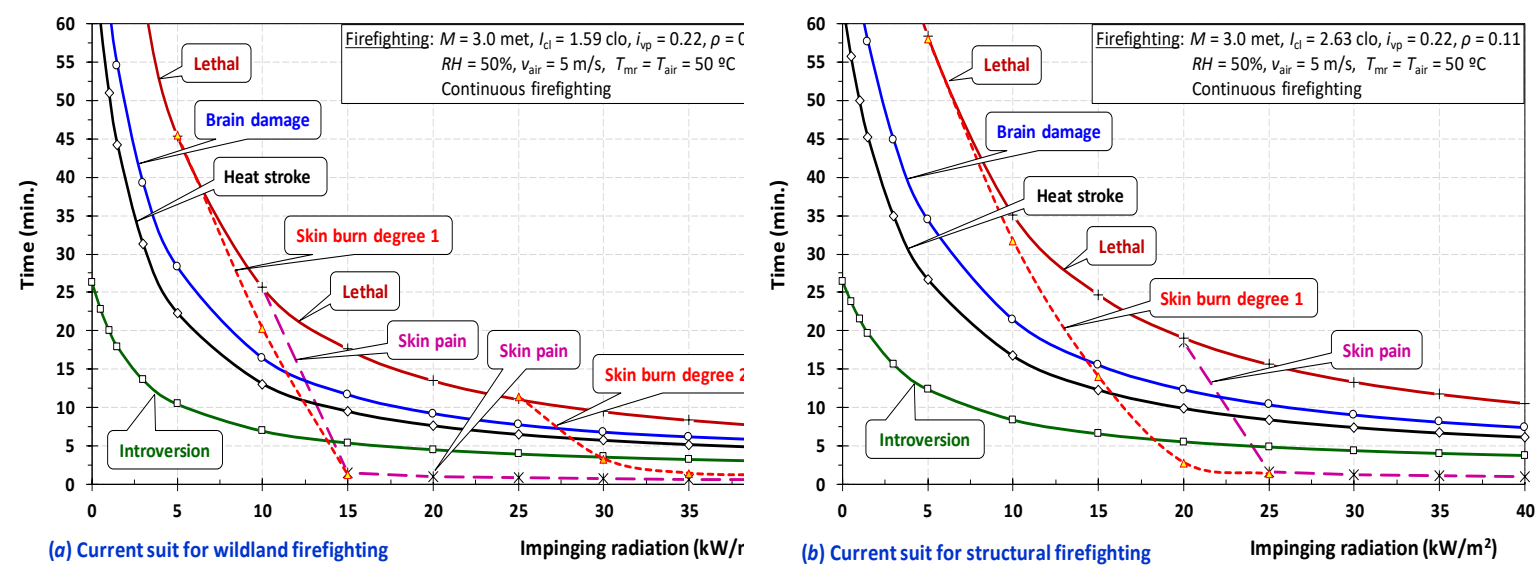

Figure 3 - Time for the onset of skin pain, of introversion, of heat stroke, of brain damage and of death as function of impinging radiation, for a complete ensemble with: (a) $I_{c l}=1.59 \mathrm{clo}$; and (b) $I_{c l}=2.63 \mathrm{clo}$.

Figure 3 show that the time (after fire impact) for the onset of heat-related illness decreases very rapidly with the increase of the incident radiation (up to about $10 \mathrm{~kW} \mathrm{~m}^{-2}$ ). For higher values of impinging radiation, these times decrease less and less until practically stabilize in a kind of minimum value. Regardless the fire intensity, and if protected with a full ensemble with $I_{c l} \geq 1.59$ clo, it will be possible to resist up to about 5 minutes without fainting. However, skin burn degree 2 can happen for ensembles with $I_{c l}=1.59$ clo if $I_{r a d} \geq 25 \mathrm{~kW} \mathrm{~m}^{-2}$. In addition, skin pains start too soon for high levels of impinging radiation. For instance, the onset of skin pain is below one minute of exposure in the case of wearing full clothing with $I_{c l}=1.59$ clo for $I_{r a d} \geq 15 \mathrm{~kW} \mathrm{~m}^{-2}$ and in the case of $I_{c l}=2.63$ clo for $I_{\text {rad }} \geq 25 \mathrm{~kW} \mathrm{~m}^{-2}$. In short, the increase of thermal insulation of the ensemble amplify the range of impinging radiation where fainting occurs before the start of skin pain. Therefore, it is not possible to state that the increasing of the protective clothing thermal insulation will enhance firefighter's safety. In fact, a convenient control of the duration of firefighting periods and / or of the temperature of the hypothalamus (which has practically the same value as the tympanum) is crucial and therefore recommended.

A good clothing insulation protects against the incoming of external heal but also can allow the firefighter to stay in dangerous and extreme environments, and remain there for unsafe periods without any warning. Then, to avoid undesired pathologies the firefighting period must be of limited duration and followed by a recovering period.

After a firefighting period and to allow the firefighter to be able to return, as quickly as possible, safely to firefighting his, initial thermal state must be restored within a relatively short period. This is only possible through the application of an appropriate body cooling technique during the recovering time-break.

For the purposes of this work, it was selected the case of a fireman dressed in a protective clothing with $I_{c l}=2.63$ clo and exposed to a fire from which the thermal incident radiation is $I_{\text {rad }}=5 \mathrm{~kW} \mathrm{~m}^{-2}$. Considering the results presented in Figure 2, a 20-minute firefighting period was selected. Therefore, the following phase sequence was assumed: neutral (60 minutes), pre-firefighting (60 minutes), firefighting (20 minutes) and recovering (unlimited time).

On the recovering period, the firefighter is far from the fire front $\left(I_{r a d}=0\right)$, has a low level of activity $(M=1.2 \mathrm{met})$ and drinks $0.33 \mathrm{~kg}$ of water at $15^{\circ} \mathrm{C}$. Six alternative body cooling techniques were analyzed.

PC - Passive cooling: the firefighter rest in a shaded environment with $T_{\text {air }}=T_{m r}=30^{\circ} \mathrm{C}, v_{\text {air }}=3 \mathrm{~m} / \mathrm{s}$ and $R H_{\text {air }}=50 \%$, and is dressed in his protective clothing, but without the helmet, the balaclava, the coat and the gloves $\left(I_{c l}=1.0\right.$ clo, $i_{v p}=0.47, \rho=0.1$ and $\left.m_{c l}=3.08 \mathrm{~kg}\right)$. 
HFIW20: The previous situation reinforced with the immersion of hands and forearms in water at $T_{\text {water }}=20^{\circ} \mathrm{C}$.

HFIW10: The passive cooling reinforced with the immersion of hands and forearms in water at $T_{\text {water }}=10^{\circ} \mathrm{C}$.

UIJ: The passive cooling reinforced with the using of an ice jacket.

UIJ + HFIW10: The passive cooling reinforced with the using of an ice jacket and the immersion of hands and forearms in water at $T_{\text {water }}=10^{\circ} \mathrm{C}$.

ABIW25: All body (except head and neck) immersion in water at $T_{\text {water }}=25^{\circ} \mathrm{C}$. In this case $I_{c l}=0.1 \mathrm{clo}, i_{v p}=0, \rho=0.1$ and $m_{c l}=0.2 \mathrm{~kg}$.

To serve as a reference, Figure $4 a$ shows the predicted results for the case of passive cooling (PC) where the evolution with time of hypothalamus, rectal, body average and maximum skin temperatures is presented. The two horizontal lines identify the threshold values for the beginning of introversion and of heat-stroke. The start of the fire thermal impact occurs at instant zero on the time axis. For comparative evaluation, Figure $4 b$ shows that the evolution of the heat stored in the human body [in $\mathrm{kJ} / \mathrm{kg}$ ], as function of time, for all body cooling techniques tested.
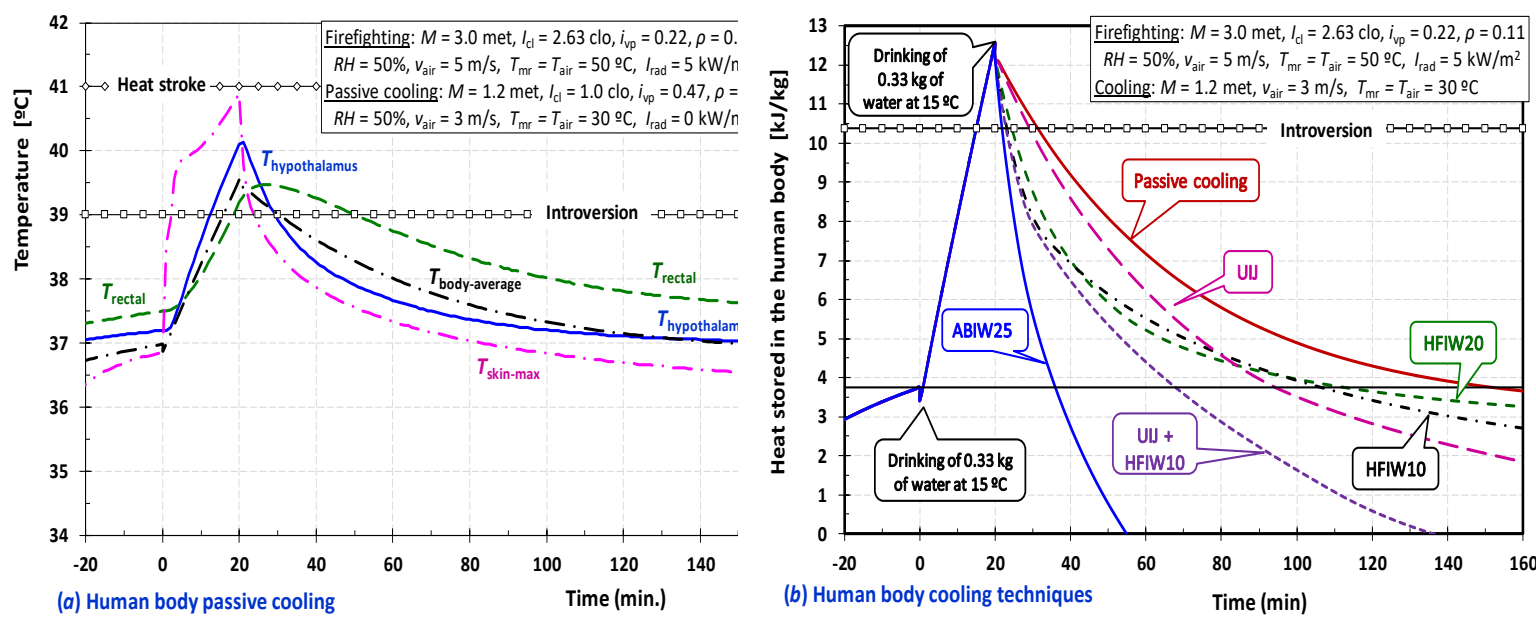

Figure 4 - Time evolution of human body temperatures and heat stored: (a) Passive cooling; and (b) heat stored in the human body for all body cooling techniques tested.

As can be observed from Figure 4, the drinking of cold water has only a very small influence on the reduction of firefighter thermal stress. However, drinking water is important for hydration purposes.

Although with very different effectiveness, all body cooling techniques considered proved to be capable to mitigate the level of hyperthermic stress of firefighters. In the situation considered, the passive cooling attenuates the heat stress but it is the less effective of all. Both cooling techniques where the passive cooling is reinforced by immersion of the hands and of the forearms in water (HFIW20 and HFIW10) have similar effectiveness. However, a slightly advantage exist when $T_{\text {water }}=10^{\circ} \mathrm{C}$, despite the appearance of vasoconstriction and eventually shivering when the water is at $10^{\circ} \mathrm{C}$.

For the situation considered, the cooling techniques tested can be ordered from the less effective to the highest one as: $6^{\text {th }}$ PC - passive cooling; $5^{\text {th }}$ ) UIJ - use of an ice jacket; $4^{\text {rd }}$ ) HFIW20 - immersion of hands and forearms in water at $T_{\text {water }}=20^{\circ} \mathrm{C} ; 3^{\text {rd }}$ ) HFIW $10-$ the same but with $T_{\text {water }}=10^{\circ} \mathrm{C} ; 2^{\text {nd }}$ ) UIJ + HFIW10 - use of an ice jacket reinforced by immersion of hands and forearms in water at $T_{\text {water }}=10^{\circ} \mathrm{C}$; and $1^{\text {st }}$ ) ABIW25 - all body (except head and neck) immersion in water at $T_{\text {water }}=25^{\circ} \mathrm{C}$. 
Among the tested, the strategy of immersion the entire body in water at $25^{\circ} \mathrm{C}$ is undoubtedly substantially more effective than the others. This is the one with the highest cooling rate, the lowest temperature values and lowest heat stored in the human body. Therefore, whenever feasible, it should be selected.

\section{Conclusions}

The protocol adopted in the present work submits the firefighter to four phases: neutral (stabilization), pre-firefighting, firefighting and recovering. Six alternative body cooling techniques were analyzed, which are applied during the recovering period.

From a safety point of view, the introversion threshold is a good indicator for exposure limits that must not be exceeded. Due to the nearest instantaneous onset of skin pain, only fires with incident radiation fluxes $I_{\mathrm{rad}}<1.5 \mathrm{~kW} \mathrm{~m}^{-2}$ can be fought without wearing ensembles that completely cover the firefighter skin. The time to the onset of heat-related illness decreases very rapidly with the increase of the incident radiation. On the contrary, time safety intervals increase with the clothing thermal insulation. This is evident when passing from the value of 1 to 3 clo. For higher values, the effect is less pronounced. However, protective clothing ensembles with intrinsic insulating values above 3 clo are not practical to use. Regardless the fire intensity, and if protected with a full ensemble with $I_{c l} \geq 1.59 \mathrm{clo}$, it will be possible to resist up to about 5 minutes without fainting. Even so, skin pain starts too soon for high levels of impinging radiation and burn degree 2 can occur. Thus, high thermal insulation may or not enhance safety. Therefore, a convenient control of the duration of firefighting periods is crucial

For the situation of $I_{\text {rad }}=5 \mathrm{~kW} \mathrm{~m}^{-2}$ and an active fighting period of 20 minutes, the cooling techniques tested can be ordered from the less effective to the highest one as: $6^{\text {th }}$ ) passive cooling; $5^{\text {th }}$ ) use of an ice jacket; $4^{\text {rd }}$ ) immersion of hands and forearms in water at $20^{\circ} \mathrm{C} ; 3^{\text {rd }}$ ) the same but with water at $10^{\circ} \mathrm{C} ; 2^{\text {nd }}$ ) use of an ice jacket reinforced by immersion of hands and forearms in water at $10^{\circ} \mathrm{C}$; and $1^{\text {st }}$ ) all body (except head and neck) immersion in water at $25^{\circ} \mathrm{C}$. Among the tested, the strategy of immersion the entire body in water at $25^{\circ} \mathrm{C}$ is undoubtedly more effective than the others.

\section{References}

Abreu RM, Raimundo AM, Quintela DA (2014). Analysis of the thermophysiological response to cooling techniques in firefighters, ICFFR 2014 - 7th International Conference on Forest Fire Research, paper H01 (pp. 1-3), Coimbra, Portugal, 14 - 21 november 2014.

Barr D, Gregson W, Sutton L, Reilly T (2009). A practical cooling strategy for reducing the physiological strain associated with firefighting activity in the heat, Ergonomics 52(4): 413-420.

Bröde P, Kuklane K, Candas V, DenHartog EA, Griefahn B, Holmér I, Meinander H, Nocker W, Richards M, Havenith G (2010). Heat gain from thermal radiation through protective clothing with different insulation, reflectivity and vapour permeability, International J. Occupational Safety and Ergonomics 16(2): 231-244.

Carballo-Leyenda B, Villa JG, Lopez-Satué J, Jose A. Rodríguez-Marroyo JA (2017), Impact of different personal protective clothing on wildland firefighters' physiological strain, Frontiers in Physiology 8: Article 618.

Carter JB, Banister EW \& Morrison JB (1999). Effectiveness of rest pauses and cooling in alleviation of heat stress during simulated fire-fighting activity, Ergonomics 42: 299-313.

Colburn D, Suyama J, Reis S (2011). A comparison of cooling techniques in firefighters after a live burn evolution, Prehospital Emergency Care 15: 226-232. 
Chou C, Tochihara Y, Kim T (2008). Physiological and subjective responses to cooling devices on firefighting protective clothing, European J Applied Physiology 104: 367-374.

EN 1473 (2016). Installation and equipment for liquefied natural gas - design of onshore installations, European Standard, European Committee for Standardization.

Fiala D, Lomas KJ, Stohrer M (1999). A computer model of human thermoregulation for a wide range of environmental conditions - the passive system, J Applied Physiology 87: 1957-1972.

Fontana P, Saiani F, Grütter M, Croset J-P, Capt A, Camenzind M, Morrissey M, MacRae BA, Rossi RM, Annaheim S (2017). Thermophysiological impact of different firefighting protective clothing ensembles in a hot environment, Textile Research Journal 88(7): 744-753.

Giesbrecht GG, Jamieson C, Cahill F (2007). Cooling hyperthermic firefighters by immersing forearms and hands in $10^{\circ} \mathrm{C}$ and $20^{\circ} \mathrm{C}$ water, Aviation Space Environmental Medicine 78: 561-567.

Havenith G, Heus R (2000). Ergonomics of protective clothing, Proc. of Nokobetef 6 and 1st European Conference on protective clothing, Stockholm, Sweden, May 7-10.

Havenith G, Holmér I, Parsons K (2002). Personal factors in thermal comfort assessment - clothing properties and metabolic heat production, Energy and Buildings 34: 581-591.

Henriques F (1947). Studies of thermal injury V. The predictability and the significance of thermally induced rate processes leading to irreversible epidermal injury, Archives of Pathology 43: 489-502.

Hostler D, Reis S, Bednez JC, Kerin S, Suyama J (2010). Comparison of active cooling devices with passive cooling for rehabilitation of firefighters performing exercise in thermal protective clothing: a report from the Fireground Rehab Evaluation (FIRE) trial, Prehospital Emergency Care 14: 300309.

Kenney W, DeGroot D, Holowatz L (2004). Extremes of human heat tolerance - life at the precipice of thermoregulatory failure, J Thermal Biology 29: 479-485.

Konz S, Hwang C, Dhiman B, Duncan J, Masud A (1977). An experimental validation of mathematical simulation of human thermoregulation, Computers in Biology and Medicine 7: 71-82.

Lopez RM, Cleary MA, Jones LC, Zuri RE (2008). Thermoregulatory influence of a cooling vest on hyperthermic athletes. J Athletic Training 43(1): 55-61.

McLellan TM, Selkirk GA (2005), The management of the heat stress for the firefighter, DRDC, Canada.

McQuerry M, Barker R, DenHartog E (2018). Relationship between novel design modifications and heat stress relief in structural firefighters' protective clothing, Applied Ergonomics 70: 260-268.

Mündel T, King J, Collacott E, Jones DA (2006). Drink temperature influences fluid intake and endurance capacity in men during exercise in a hot dry environment, Experimental Physiology 91(5): 925-933.

Pascoe DD, Bellingar TA, McCluskey BS (1994). Clothing and exercise II. Influence of clothing during exercise/work in environmental extremes, Sports and Medicine 18: 94-108.

Quintela DA, Gaspar AR, Borges C (2004). Analysis of sensible heat exchanges from a thermal manikin, European J Applied Physiology 92(6): 663-668.

Raimundo AM, Gaspar AR, Quintela DA (2004). Numerical modelling of radiative exchanges between the human body and surrounding surfaces. Climamed $2004-1^{\text {st }}$ Mediterranean congress of climatization, 16-17 of April, Lisbon, Portugal, paper 8/1.

Raimundo AM, Figueiredo AR (2009). Personal protective clothing and safety of firefighters near a high intensity fire front, Fire Safety Journal 44: 514-521.

Raimundo AM, Quintela DA, Gaspar AR, Oliveira AVM (2012). Development and validation of a computer program for simulation of the human body thermophysiological response, Portuguese chapter of IEEE-EMBS, ISBN:978-1-4673-4524-8. 
Raimundo AM, Pereira CD, Quintela DA, Oliveira AVM (2015). Human body thermoregulation - test and validation of a computer program, SHO 2015 - International Symposium on Occupational Safety and Hygiene, paper 25, Guimarães, 12 - 13 February.

Raj PK (2008). A review of the criteria for people exposure to radiant heat flux from fires, J Hazardous Materials 159: 61-71.

Rossi JL, Simeoni A, Moretti B, Leroy-Cancellieri V (2011). An analytical model based on radiative heating for the determination of safety distances for wildland fires, Fire Safety Journal 46: 520 527.

Sharkey BJ (1999), Heat stress - wildland firefighter health and safety recommendations, April 1999 Conference, Missoula Technologic and Development Center, USDA Forest Service, Montana.

Selkirk G, McLellan TM \& Wong J (2004). Active versus passive cooling during work in warm environments while wearing firefighting protective clothing, J. Occupational Environment and Hygiene 1: 521-531.

SFPE Task Group on Engineering Practices (2000). Predicting 1st and 2nd degree skin burns from thermal radiation, Society of Fire Protection Engineers, Bethesda, MD.

Stoll A, Greene L (1959). Relationship between pain and tissue damage due to thermal radiation, J Applied Physiology 14: 373-382.

Stolwijk JAJ (1971). A mathematical model of physiological temperature regulation in man. NASA Contractor Report CR-1855, NASA, Washington, DC.

Tanabe S, Kobayashi K, Nakano J, Ozeki Y, Konishi M (2002). Evaluation of thermal comfort using combined multi-node thermoregulation $(65 \mathrm{MN})$ and radiation models and computational fluid dynamics (CFD), Energy and Buildings 34: 637-646.

Wenger CB (1988). Human heat acclimatization, In: Pandolf K, Sawka M, Gonzalez R, eds, Human performance physiology and environmental medicine at terrestrial extremes. Indianapolis Benchmark Press (now: Cooper Publishing Group), pp. 153-197. 